\title{
Socialisation, Trust and Reciprocity among Young People
}

\author{
Matteo Mighelia
}

JEL-Classification: C93, D01, Z13

Keywords: trust, reciprocity, social capital

\section{Introduction}

One of the major challenges of today's microeconomics is to understand the psychological motivations of trust and reciprocity, since they (reciprocity in particular) are source of voluntary cooperation and economic incentives (FeHR and FALK, 2002). Indeed incentives are a major motivation for the action of the economic agents (EASTERLY, 2001), and voluntary cooperation is the basis of the provision of several important services (such as elderly care, public goods, etc.). Trust and reciprocity are a fundamental ingredient of the economic life: "[trust] is an important lubricant of a social system. It is extremely efficient; it saves a lot of trouble to have a fair degree of reliance on other people's word" and similar values, loyalty, or truth telling are examples of what an economist would call 'externalities.' They are goods; they are commodities; they have real practical value; they increase the efficiency of the system, enable you to produce more goods or more of whatever the values you hold in high esteem. But they are not commodities for which trade on the open market is technically possible or even meaningful" 2 .

Grounding on the extant economic and psychological literatures, this paper aims at inquiring into the factors that enhance trust and reciprocity at young ages. On the one hand the psychologists include trust and reciprocity among the factors which define the positive development ${ }^{3}$ of one's personality (Furano et al., 1993, Tierney, Grossman and Resch, 1995 and Hurtes et al., 2000) and claim that socialisation is among the causes of high levels of generalised trust

a Lecturer of Mathematics, University of Eastern Piedmont. E-mail: matteo.migheli@sp.unipmn.it.

1 Arrow (1974), p. 23.

2 Ibidem.

3 For further details on what the psychologist mean with "positive development, see LARson (2000). 
and reciprocity (Hansen, Larson and Dworkin, 2003); on the other hand the economists have found a link between these and several economic variables (Durlauf and Fafchamps 2005). Hence these results taken together seem to suggest that socialisation fosters trust and reciprocity, which, in turn, have a positive influence on economic factors.

The simplest way to socialise is hanging out with friends, but also joining voluntary organisations and participating to their activities is a way of socialising. In the framework of the literature on social capital, this means that accumulating relational social capital (Putnam, 1993) enhances the positive development of the young. The focus of the paper is to understand if, among the features of this positive development, also trust and reciprocity are facilitated by the accumulation of relational social capital. In other words I aim at analysing if a link between socialisation and generalised trust exists. The evidence of the paper allows for concluding that spending time in activities promoted by voluntary youth organisations is positively linked with both generalised trust and reciprocity. These results, together with those of the psychological literature, suggest that socialisation, at least among the young, enhances both trust and reciprocity, which are, thus, not just "innate". These are fundamental for an economy to work and knowing that they can be promoted through the accumulation of associative social capital opens new perspective of policy, especially in the developing countries.

The results of an experiment conduced with undergraduate students will provide the empirical evidence supporting the conclusion mentioned before. Section 2 will provide details on the relationships between relational social capital and positive development, while Section 3 will describe the experiment and its suitability to answer the question addressed by the paper.

\section{Related Literature}

The sociological and psychological literatures suggest that participation to social networks helps to develop positive attitudes, among which the so-called generalised trust. The most of the psychological and sociological studies are based on natural experiments, i.e. the authors observe people who have been subject to some "treatment", i.e. people who have experienced given types of socialisation, either voluntarily (and I will call this case "voluntary socialisation"), or because involved in specific programmes (and I will refer to these cases as "induced socialisation”). Harter (1990), Kleiber and Kirshnit (1991), Larson (1994) and KLEIBER (1999) studies belong to the first type (i.e. they observe the effects 
of voluntary socialisation) and show that experimentation with social roles and value achievements are associated with leisure behaviour and socialization (for instance within sports teams). In youth organizations people learn how to behave in a group and how to cooperate for reaching common goals (LARson, 2000; Rich, 2003 and Jarret, Sullivan and Watkins, 2005). This entails learning to trust peers and to expect reciprocity from them, as well as developing an altruistic behaviour. Several studies provide evidence for the significant and large impact of associative life on positive development ${ }^{4}$ (see for example Furano et al., 1993; Tierney, Grossman and Resch, 1995 and Hurtes et al., 2000); using longitudinal data LARSON (1994) shows that participation in youth organizations enhances pro-social behaviour and that it is uniquely situated to achieve leadership, altruism and civic engagement (LARsON, 2000).

A major attitude fostered by the positive development is the capacity to trust the other people and to reciprocate (WeISSBERg and O'Brien, 2004). Brehm and RAHN (1997) find evidence on a two-way causality, but with a stronger impact of social participation on trust than the other way. This result is confirmed by Shah (1998). Also Claibourn and Martin (2000) conclude that generalized trust originates from social participation. LARSON (2000) states that the rich context of youth associations promotes both initiative and "other positive qualities from altruism to identity"s. UsLaner (2002) finds that greater trust comes from voluntary and charitable activities, rather than the opposite. JarRet, Sullivan and Watkins (2005) assess that social relationships provide the youth with access to resources which enhance their attitudinal social capital (i.e. generalized trust). Jennings and STOKer (2004) reach a mixed conclusion on the direction of causality: generalized trust seems to be more a cause than a consequence of civic engagement, but they are interdependent. Several works support the hypothesis of causality to go from participation to voluntary associations to the individual development of positive attitudes, whilst the viceversa (i.e. positive attitudes determine participation in associations) is generally rejected. These works suggest that on the one hand socialisation promotes the individual's positive development, and on the other this helps people to develop generalised trust and reciprocity. The idea behind all of them is that people acquire trust by socialising with peers.

4 It is worthy to stress that "positive development" refers to a set of attitudes (such as the capacity of initiative, of socialising, of taking decisions, etc.) so defined by the psychologists (see for example LaRson, 2000).

5 Larson (2000), p. 178. 
If on the one hand the psychological literature emphasises the role of trust and reciprocity as "components" of the positive development of an individual, on the other hand the economic literature highlights the importance of these two attitudes for economic development and growth (Durlauf and FafChamps, 2005 and Karlan, 2005). In addition Harris-White (2003) and YUNUS (2003) show how trust and reciprocity are important for accessing credit in developing countries, and how they can serve as collaterals on the credit market. However, while it has paid great attention to the link between trust and other relevant economic variables, the economic literature has neglected to inquiry into the causes of generalised trust and reciprocity, which are relevant not only from an empirical point of view, as mentioned, but also theoretically (Rotemberg, 2004). The psychological literature mentioned before constitutes both an excellent starting point and an encouraging theoretical framework for inquiring the relationship that exists between socialisation on one side and trust and reciprocity on the other.

It is noteworthy that some few attempts in this sense have already been made, mainly by experimental and behavioural economists. The reason why the studies on the topic have involved above all experimental protocols is probably that these allow for an excellent isolation of the variables of interest and for the design of targeted games. So for instance, using a "trust game" (BERG, Dickhaut and McCabe, 1995), Mighel (forthcoming) shows the existence of a positive link between the outcomes of a trust game and active membership to political parties and to religious and youth organisations, but does not analyse the link between these last and generalised trust in depth; namely he does not account for the effect of spending time with friends. Here my focus is on the link between active membership to youth organisations and hanging out with friends on the one side and trust and reciprocity on the other side. My results are consistent with those of HANSEN, LARSON and DwORKIN (2003), three psychologists who studied the impact on youth's trust and reciprocity. Their paper examines the outcomes of a basic trust game, linking the participants' choices with time spent hanging out with friends, and/or within youth voluntary organizations. The authors consider a large number of them: faith-based and service activities, academic and leadership activities, fine arts activities, participation in community organisations and vocational clubs and sports. They find that different activities are linked to the development of different attitudes: the members of faith-based associations and those performing community and vocational activities are particularly pro-social and tied to their community, in addition they show a high level of identity development and perceive themselves as highly integrated in the society ${ }^{6}$. Although the authors 
do not mention generalised trust and reciprocity explicitly, these can be easily related to the sense of community and the pro-social attitudes.

\section{Methodology and Data}

Following the extant literature on the topic, the inquiry presented in this paper is based on a baseline trust game, played by Norwegian undergraduate students: a total of 257 valid $^{7}$ students from the University of Oslo participated to the experiment, evenly divided into two groups (A and B).

Players were students at the School of Economics, but were selected so that they had no previous notions of game theory. One might argue the existence of some self-selection of the students when enrolling a university school, and claim that this reflects in their behaviour when playing games with money. However experiments aimed at detecting behavioural differences in this sense have always given a negative answer (STANLey and Tran, 1998 and Meier and Frey, 2004). They were invited to participate to the experiment verbally by the professors during regular classes on day "x" for the next day. There was no limit to the maximum number of students willing to participate. This procedure of selection is not neutral: Eckel and Grossman (2000) find that the subjects recruited verbally in a classroom (so-called "pseudo-volunteers") are more generous on average than those recruited in the usual way ${ }^{8}$ (so-called "volunteers"). However KRAWCZYK (2011) suggests that this is due to the fact that the volunteers are attracted by money more than the average of the population (i.e. they participate to the experiment with the main scope of earning money), hence the

6 In addition the authors highlight that: sports are associated with self-knowledge and emotional control; arts, academic and leadership activities show a positive, but low correlation with the variables of interest for the authors, who nevertheless conclude that, though to different extents, the socialisation among young people fosters what the psychologists call "positive development".

7 The total number was larger: here I consider only the retained observations, i.e. the total number of participants minus the number of those who filled in the forms in an improper way. Hence, the even number (257) is due to students who wrote signs on the forms of the experiment or did not understand the instructions. In particular when the signs (e.g. names) written on the form made the responder identifiable the form (and thus the subject) was dropped from the sample. Players were informed verbally that any sign on the forms different from the indispensable ones would have been reason of exclusion.

8 That is those who respond to announcements published in the school and/or to invitations via email. 
use of pseudo-volunteers would be more representative of the actual population than a sample of pure volunteers.

The participants were not explained the game, but were said that two sessions (one in the morning and the other in the afternoon) would have taken place, and were therefore requested to be available for both. Indeed on day " $\mathrm{x}+1$ " the experimenter (who was unknown to the students) split up the group of volunteers evenly and randomly into two subgroups (A and B). Although they were all undergraduate students, and thus they are not representative of the whole population, the validity of this type of sample and of the relative results relies on Stolle and Hooghe (2004), who note that the experiences had when young are important explicators of the behaviour when adult. Hence an analysis based on undergraduate students offers, anyway, some possibility of generalization.

Given the lack of an experimental laboratory in Oslo, the experiment was played on paper forms. Students were disposed in a large classroom so that they could not (at least without visible and considerable effort) look at others' forms. In addition players $\mathrm{A}$ (the trustors) and $\mathrm{B}$ (the trustees) played in two different classrooms, the former in the morning, and the latter in the afternoon in order to prevent people from the two groups to meet. They were also told that each of them would have been randomly matched with a person of the other sub-group. While it is true that the two subgroups saw each other before and during the splitting, given their high numerous, the random matching and the anonymity should have minimised the risk that some previous acquaintance had influenced the game.

The trust game is a sequential blind game with completely symmetric information (i.e. all the players have the same set of information ${ }^{9}$ ), involving two players, say $\mathrm{A}$ and $\mathrm{B}$. A receives an initial endowment and has the possibility of giving a part (between 0 and all) to $B$. Then the experimenter automatically triples the amount that the trustor (A) decides to pass to $\mathrm{B}$ and gives it to the latter; at this point the trustee (B) has to decide which share (between 0 and all) of the received amount he wants to pass back to $A$. This ends the game. As mentioned before, the game was played on paper forms (see the Appendix for its English translation). Each player A received a form and had to fill in the upper half with the amount he decided to pass to player $\mathrm{B}$. Then the forms were returned to the experimenter who filled in the upper line of the second half, indicating the amount $B$ received from A (i.e. the triple of what written in the upper half). Eventually each subject $B$ received one of these forms and had to fill in the last line with the sum

9 Available upon request. 
he chose to pass back to the A he was matched to. A brief questionnaire aimed at measuring social participation and other individual characteristics followed the game (i.e. students were given first the form of the game and played it, and then were given and filled in the questionnaire). The experiment lasted between ten and fifteen minutes (questionnaire included), as initially announced to the students. Players A were endowed with a notional amount of $1,400 \mathrm{NOK}^{10}$; at the end of both phases of the experiment (i.e. after both A and B had played), a lottery indicated the three couples to be actually paid, according to the results of their decisions ${ }^{11}$. The students were then paid separately ${ }^{12}$ in the secretary of the Department of Economics of the University of Oslo (which is in the same building as the School of Economics).

The questionnaire collected information about the respondent's socialisation (i.e. time spent with friends, within youth voluntary organizations and sporting) and the usual socio-demographic characteristics: gender, living alone or with parents, having or not a job ${ }^{13}$, and the number of sisters and of brothers (whose presence generates a social network with special peers) were recorded. These variables are used as additional controls in the regressions, as well as for providing descriptive statistics. In order to account for the "kindness effect" (McCABE, Rigdon and SMITH, 2003), when analyzing the amounts passed back by players of type $\mathrm{B}$, also the received amount is used as control together with the other relevant variables.

Data are analyzed through both descriptive statistics and econometrics. Nonparametric tests (Hotelling tests) of mean equality are performed with respect to membership, gender, having a job and having relatives. Multivariate analysis involves OLS regressions to inquiry the impact of socialization given the effect of the other controls. The lack of significant correlation among used variables is also tested. As for the different impulse of hanging out with friends, sporting and spending time within voluntary youth organizations, I expect both the coefficients to be positive and significant.

10 The initial endowment was set on a "strange" level on purpose to avoid anchor effects as much as possible.

11 This entails an expected hourly-equivalent payment between 140 and 420 NOK.

12 Being the game simultaneous, it would have been impossible to gather all the players A together once more, and to pay students in front of all; it would have been possible for players B, but this would have created an asymmetry. In turn, this could have engendered some distortion, as it is possible that people retrieve some utility from being "prised" in public. The procedure adopted is therefore that which minimises these potential distortions.

13 The rationale is that earning a wage and/or spending own money for rents and food can modify people's (marginal) utility of money. 
An important innovation with respect to the extant literature is how people's involvement in social activities is measured. In general economists and political scientists (see Putnam, 1993 and Durlauf and Fafchamps, 2005) take into account membership or non-membership only (i.e treat social capital as a sum of dummies) or the self-assessed level of active participation (JenNings and STOKer, 2004). Each of these measures suffers of at least one weakness: accounting for membership only (and not also for its intensity) does not allow for quantifying the actual level of social relationships of the member. In other words: it is the number and the frequency of social contacts that is relevant to affect individuals' trust and reciprocity (Migheli, forthcoming). Furthermore, the subjective concept of "active participation" is likely to be different across responders. The measure I use here does not feature these problems, although it relies on the implicit assumption that one hour spent in an activity generates the same benefit for anybody. Here I measure involvement by the average time that a player spends - per week - in each of the considered social activities. However for completeness and for the sake of comparability with the previous studies, this paper presents also some results (based on statistical tests) based on the simple dicotomy member/non-member.

I consider also time spent in practicing sports and in hanging out with friends. On the one hand sporting represents a major activity for young people; on the other hand team sports are likely to contribute to positive development. The main hypotheses are that hanging out with friends and participating to activities of youth organizations are positively correlated with passed amounts in both the stages of a trust game.

It is noteworthy that when the results of subjects $B$ are analysed, those who received $0 \mathrm{NOK}$ by their $\mathrm{A}$ mates are excluded from the sample (as they had no choice than passing back $0 \mathrm{NOK}$ ).

\section{Results}

First I present the results for Group A and then those for Group B; for each group, descriptive statistics are presented before OLS regressions.

Students from Group A passed 56.0\% of the initial endowment on average, with some (9 representing 6\% of the sample) who played the Nash equilibrium (i.e. passed nothing) and some (29, representing $18.7 \%$ of the sample) who passed the whole endowment. The group is unbalanced with respect to gender, as female participants represented the $55.5 \%$; however this proportion reflects the students' gender distribution in the School (i.e. to say that the composition of the sample is not biased under this aspect). 
Most of the students live alone and have a job (see Table 1). More than one half practice sport and with respect to which no significant gender difference is detected. Only $9.0 \%$ of the sample are members of youth organizations ${ }^{14}$, but members spend a considerable amount of time within them (again no gender difference is found). Hanging out with friends appears to be the most common and time-consuming activity among those considered.

Table 1: Descriptive Statistics for Sub-Group A

\begin{tabular}{lc}
\hline & Mean \\
\hline Passed amount (\% of the initial endowment) & 56.0 \\
\hline Time spent $^{(2)}$ in (average weekly hours): & $5 \mathrm{~h} 05 \mathrm{~m}$ \\
sports associations & $8 \mathrm{~h} 20 \mathrm{~m}$ \\
youth organizations & $2 \mathrm{~h} 55 \mathrm{~m}$ \\
students' organizations & $14 \mathrm{~h} 30 \mathrm{~m}$ \\
hanging out with friends & \\
\hline Members of (\% of respondents) & 56.0 \\
sports associations & 17.4 \\
students' organizations & 9.0 \\
youth organizations & 71.0 \\
\hline Live alone ${ }^{(1)}$ & 72.4 \\
Have a job $^{(1)}$ & 44.5 \\
\hline Gender: male ${ }^{(1)}$ & \\
\hline
\end{tabular}

Notes: (1) percentage of respondents; (2) for associations, time spent by members only.

Table 2 presents Hotelling's tests of mean comparison for members and nonmembers of the considered associations. The tested variable is the passed stake as a percentage of the initial endowment. Only membership to sports or youth voluntary organizations shows a significant link with the passed amounts. It is worthy to notice that membership to youth organizations is associated with

14 This figure is consistent with other sources of data. For example, the World Value Survey, for the period 1989-2004, reports that the share of students members of youth organisations has been $12.5 \%$ on average, and that it has been decreasing over time. 
higher stakes, while practicing sports has the opposite correlation (perhaps as a consequence of the fact that sports prize merit, which is absent in the current game). As all the participants spend time out with friends, here the two subsamples to be compared are constructed in a different way: one of the two subsamples comprehends people who spend less than or exactly the time spent on average by the whole sample in a given association/activity, while the other subsample is complementary to the first. Spending more time than the average with friends does not show any significant correlation.

Table 2: Passed Amounts (\% of the Initial Endowment). Hotelling test for Mean Equality comparison

\begin{tabular}{lccc}
\hline & Members & Non-members & p-value \\
\hline Youth organizations & 69.7 & 54.2 & 0.09 \\
Sports associations & 51.6 & 61.7 & 0.09 \\
Students' associations & 57.5 & 55.7 & 0.81 \\
Friends $^{(1)}$ & 53.6 & 57.9 & 0.47 \\
\hline Males & 54.5 & & 0.72 \\
Females & 56.8 & & 0.23 \\
\hline Having a job & 57.6 & 48.8 & 0.47 \\
Living alone & 57.3 & 52.0 & \\
\hline
\end{tabular}

Notes: (1) Here I divide the groups according to spending more or less time than the average hanging out with friends.

The OLS regressions (Table 3) highlight a coefficient for the time spent within youth organizations that is positive and significant; it is also robust to the addition of other controls. The coefficients spending time out with friends are never significant, although the latter has the expected sign. Sporting relates negatively with trust, probably because it educates people to competitiveness and to prizing merit, or even to approaching games more strategcally than the average of the population. This represents a confirmation of the initial hypothesis, after which trust and reciprocity are "built" through the participation to the activities of youth organizations rather than playing sports or hanging out with friends. In other words, time spent within youth voluntary associations is more productive than time spent hanging out with friends or sporting. 
Table 3: OLS Regressions for Amounts Passed by Players of Type A (s.e. in Parentheses)

\begin{tabular}{|c|c|c|c|c|}
\hline & 1 & 2 & 3 & 4 \\
\hline Youth organizations & $\begin{array}{c}0.021 \\
(0.006)^{* * *}\end{array}$ & $\begin{array}{l}0.021 \\
(0.005)^{* * *}\end{array}$ & $\begin{array}{l}0.020 \\
(0.005)^{* * *}\end{array}$ & $\begin{array}{l}0.020 \\
(0.004)^{* * *}\end{array}$ \\
\hline Sports organizations & $\begin{array}{l}-0.018 \\
(0.009)^{*}\end{array}$ & $\begin{array}{l}-0.018 \\
(0.009)^{* *}\end{array}$ & $\begin{array}{l}-0.018 \\
(0.009)^{*}\end{array}$ & $\begin{array}{l}-0.022 \\
(0.008)^{* * *}\end{array}$ \\
\hline Students' organizations & $\begin{array}{c}0.001 \\
(0.010)\end{array}$ & $\begin{array}{c}0.001 \\
(0.010)\end{array}$ & $\begin{array}{c}-0.001 \\
(0.010)\end{array}$ & $\begin{array}{c}-0.000 \\
(0.009)\end{array}$ \\
\hline Friends & $\begin{array}{c}-0.001 \\
(0.003)\end{array}$ & $\begin{array}{c}0.001 \\
(0.010)\end{array}$ & $\begin{array}{c}0.000 \\
(0.010)\end{array}$ & $\begin{array}{c}-0.009 \\
(0.010)\end{array}$ \\
\hline Friends 2 & & $\begin{array}{c}-0.000 \\
(0.000)\end{array}$ & $\begin{array}{c}-0.000 \\
(0.000)\end{array}$ & $\begin{array}{c}-0.000 \\
(0.000)\end{array}$ \\
\hline Male & $\begin{array}{c}-0.001 \\
(0.072)\end{array}$ & $\begin{array}{c}-0.003 \\
(0.073)\end{array}$ & $\begin{array}{c}-0.018 \\
(0.073)\end{array}$ & $\begin{array}{c}-0.051 \\
(0.073)\end{array}$ \\
\hline Living alone & $\begin{array}{c}0.036 \\
(0.080)\end{array}$ & $\begin{array}{c}0.035 \\
(0.075)\end{array}$ & $\begin{array}{c}0.045 \\
(0.081)\end{array}$ & $\begin{array}{c}0.023 \\
(0.081)\end{array}$ \\
\hline Having a job & $\begin{array}{c}0.028 \\
(0.078)\end{array}$ & $\begin{array}{c}0.029 \\
(0.075)\end{array}$ & $\begin{array}{c}0.013 \\
(0.076)\end{array}$ & $\begin{array}{c}-0.058 \\
(0.076)\end{array}$ \\
\hline Sisters & $\begin{array}{c}0.040 \\
(0.052)\end{array}$ & & $\begin{array}{l}0.090 \\
(0.045)^{* *}\end{array}$ & $\begin{array}{l}0.106 \\
(0.046)^{* *}\end{array}$ \\
\hline Brothers & $\begin{array}{c}0.031 \\
(0.025)\end{array}$ & & $\begin{array}{c}0.033 \\
(0.026)\end{array}$ & $\begin{array}{l}0.051 \\
(0.020)^{* *}\end{array}$ \\
\hline Brothers and sisters & & $\begin{array}{c}0.035 \\
(0.026)\end{array}$ & & \\
\hline Constant & $\begin{array}{l}0.510 \\
(0.116)^{* * *}\end{array}$ & $\begin{array}{l}0.500 \\
(0.145)^{* * *}\end{array}$ & $\begin{array}{l}0.458 \\
(0.168)^{* * *}\end{array}$ & $\begin{array}{l}0.650 \\
(0.143)^{* * *}\end{array}$ \\
\hline Obs. & 104 & 104 & 103 & 92 \\
\hline $\mathrm{R}$ squared & 0.101 & 0.102 & 0.138 & 0.183 \\
\hline
\end{tabular}

In order to check for the robustness of these results, model 3 and model 4 in Table 3 account also for the nationality of origin of the responders. In particular model 3 includes a dummy for being Norwegian, while model 4 is run considering only the players born in Norway. Indeed trust and reciprocity are likely to be very sensitive to the status of native or of immigrant. In all the results in both tables the time spent within youth voluntary associations has a positive and significant coefficient, as well as the number of relatives. 
A second test of robustness is to run tobit regressions censoring at $0 \%$ and $25 \%$ lower levels ${ }^{15}$ : in this way I exclude the participants who behaved perfectly selfishly (i.e. passed nothing) and those who could have been motivated by inequity aversion only, according to the model proposed by FeHr and SснміDт (1999) ${ }^{16}$. Indeed players of type A, who passed more than $25 \%$ of their endowment should be motivated also by other positive sentiments such as altruism, trust etc. The results of these tobit regressions confirm those showed in the previous tables, namely highlighting that they are not driven by the extreme values of the dataset.

Players B on average reciprocated by sending back $38.5 \%$ of the received amount. $12.7 \%$ of them played the subgame perfect Nash equilibrium and returned 0 to their partners. It is worthy to notice that none of these Nash players is member of any youth organization. Table 4 shows that players B tend to engage less than players $A$ in voluntary associations. However, despite this difference, the evidence presented in Table 5 supports the previous findings: those who are members of youth organizations reciprocated significantly more than non-members. No significant effect is detected for hanging out with friends. This finding suggests once more that structured social capital is much more relevant than non-structured social capital in the development of positive attitudes.

The OLS (see Table 6) regressions highlight that the received amount has a high, positive and very significant effect on the returned stakes, consistently with previous results. Again, the only other significant coefficient, among those which refer to socialization variables, is that of youth organizations. Time spent with friends shows a coefficient that is positive, but albeit null and in any case non significant; also the coefficient for sporting activities is not significant (and has a negative sign). Notice the importance of the received amount in determining the level of reciprocation: here this is calculated as the percentage of the initial endowment that A sent to B. In other words: this regressor is the same as the dependent variable in Table 3 . The more the player A gives to $B$ in relative terms, the more B is willing to send back, always in relative terms. Model 3 in Table 6 corresponds to model 4 in Table 3: only Norwegians are included.

The analysis of data highlights also some other minor results, which I am going to discuss briefly. Columns 3 and 4 of Table 3 suggest that also socialisation in the household has a positive effect on trust. In particular the number of

15 These levels refer to the amount passed by players A expressed as a percentage of the initial amount.

16 Notice that, given the rules of the game, if player A passes $25 \%$ of the endowment to player B and the latter does not give back anything (as a selfish rational trustor should assume), both end up with the same amount of money. 
Table 4: Descriptive Statistics for Sub-Group B

\begin{tabular}{lc}
\hline & Mean \\
\hline Passed amount (\% of the received amount) & 38.5 \\
\hline Time spent $^{(2)}$ in (average weekly hours): & \\
$\quad$ sports associations & $4 \mathrm{~h} 35 \mathrm{~m}$ \\
youth organizations & $2 \mathrm{~h} 50 \mathrm{~m}$ \\
students' organizations & $1 \mathrm{~h} 25 \mathrm{~m}$ \\
hanging out with friends & $16 \mathrm{~h} 30 \mathrm{~m}$ \\
\hline Members of (\% of respondents) & \\
sports associations & 49.9 \\
student's organizations & 12.7 \\
youth organizations & 2.9 \\
\hline Live alone ${ }^{(1)}$ & 73.2 \\
Have a job $^{(1)}$ & 68.6 \\
Gender: male $^{(1)}$ & 41.0 \\
\hline
\end{tabular}

Notes: (1) percentage of respondents; (2) for associations, time spent by members only.

Table 5: Passed Amounts (\% of the Initial Endowment). Hotelling Test for Mean Equality Comparison

\begin{tabular}{lccc}
\hline & Members & Non-members & p-value \\
\hline Youth organizations & 65.9 & 37.6 & 0.01 \\
Students' associations & 40.8 & 38.2 & 0.67 \\
Sports associations $^{\text {Friends }}{ }^{(1)}$ & 37.8 & 39.2 & 0.73 \\
\hline Males & 36.0 & 39.7 & 0.38 \\
Females & 38.0 & & 0.83 \\
\hline Having a job & 38.9 & & 0.36 \\
Living alone & 39.7 & 35.8 & 0.69 \\
\hline
\end{tabular}

Notes: (1) Here I divide the groups according to spending more or less time than the average hanging out with friends. 
Table 6. OLS Regressions for Amounts Passed by Players of Type B (s.e. in Parentheses)

\begin{tabular}{|c|c|c|c|}
\hline & 1 & 2 & 3 \\
\hline Received amount & $\begin{array}{l}0.318 \\
(0.057)^{* * *}\end{array}$ & $\begin{array}{l}0.316 \\
(0.059)^{* * *}\end{array}$ & $\begin{array}{l}0.312 \\
(0.066)^{* * *}\end{array}$ \\
\hline Youth organizations & $\begin{array}{l}0.128 \\
(0.037)^{* * *}\end{array}$ & $\begin{array}{l}0.128 \\
(0.038)^{* * *}\end{array}$ & $\begin{array}{l}0.170 \\
(0.051)^{* * *}\end{array}$ \\
\hline Sports organizations & $\begin{array}{c}-0.008 \\
(0.006)\end{array}$ & $\begin{array}{c}-0.008 \\
(0.006)\end{array}$ & $\begin{array}{c}-0.008 \\
(0.006)\end{array}$ \\
\hline Students' organizations & & & $\begin{array}{c}0.009 \\
(0.021)\end{array}$ \\
\hline Friends & $\begin{array}{c}0.000 \\
(0.001)\end{array}$ & $\begin{array}{c}0.000 \\
(0.003)\end{array}$ & $\begin{array}{c}-0.000 \\
(0.004)\end{array}$ \\
\hline Friends 2 & & $\begin{array}{c}0.000 \\
(0.000)\end{array}$ & $\begin{array}{c}0.000 \\
(0.000)\end{array}$ \\
\hline Male & $\begin{array}{c}-0.022 \\
(0.040)\end{array}$ & $\begin{array}{c}-0.023 \\
(0.041)\end{array}$ & $\begin{array}{c}-0.033 \\
(0.043)\end{array}$ \\
\hline Living alone & $\begin{array}{c}-0.021 \\
(0.035)\end{array}$ & $\begin{array}{c}-0.021 \\
(0.037)\end{array}$ & $\begin{array}{c}-0.018 \\
(0.046)\end{array}$ \\
\hline Having a job & $\begin{array}{l}0.077 \\
(0.038)^{* *}\end{array}$ & $\begin{array}{l}0.078 \\
(0.039)^{* *}\end{array}$ & $\begin{array}{c}0.064 \\
(0.043)\end{array}$ \\
\hline Sisters & & $\begin{array}{c}0.006 \\
(0.023)\end{array}$ & $\begin{array}{c}-0.008 \\
(0.023)\end{array}$ \\
\hline Brothers & & $\begin{array}{c}0.012 \\
(0.021)\end{array}$ & $\begin{array}{c}0.012 \\
(0.026)\end{array}$ \\
\hline Brothers and sisters & $\begin{array}{c}0.010 \\
(0.016)\end{array}$ & & \\
\hline Constant & $\begin{array}{l}0.150 \\
(0.061)^{* *}\end{array}$ & $\begin{array}{l}0.155 \\
(0.770)^{* *}\end{array}$ & $\begin{array}{l}0.181 \\
(0.081)^{* *}\end{array}$ \\
\hline Obs. & 95 & 95 & 86 \\
\hline $\mathrm{R}$ squared & 0.313 & 0.314 & 0.340 \\
\hline
\end{tabular}

brothers and, above all, of sisters correlates positively and significantly with the amounts passed by subjects $\mathrm{A}$. This reinforces the results obtained: brothers and sisters (provided to have any) are indeed the first peers with whom each of us has socialised in his life. However this result is not fully robust to the different specifications of the model, and is never significant for the type B group. Conversely, 
for these subjects having a job has a positive influence on reciprocity. This might be due to the fact that people who work think that money has to be earned by working, and therefore they are more "grateful" to A mates for their "gift", and show this reciprocating more than those who do not have a job ${ }^{17}$.

\section{Conclusions}

This paper aims at inquiring the findings of Hansen, Larson and DwOrkin (2003) in an economic experimental framework. These authors found that the time spent within voluntary organizations fosters the positive development of young people more than hanging out with friends. This paper tests this result within the framework of a trust game.

An important innovation with respect to the traditional literature on associative social capital is that the present work measures the social capital of players as the time spent in social activities, rather than considering only memberships to voluntary groups. Other individual variables and characteristics are considered.

The results confirm the conclusions of HANSEN, LARSON and DwORKIN (2003), and even provide some stronger evidence against time spent with friends as a catalyst for the production of trust. Although it is not possible to test the direction of causality with the data of this experiment, the causality link is assumed after the results attained by a vast psychological literature during the last two decades. Hence, given this assumption, as the results presented here are consistent with Caldwin and Baldwin (2003) and with Hansen, Larson and DworKIN $(2003)^{18}$, they seem to provide some more evidence that the participation to youth associations causes the members' social attitudes. The time spent within youth organizations shows a positive and significant correlation with both trust and reciprocity (i.e. the amounts passed by players A and players B in the game respectively). Moreover, the OLS coefficient for the time spent hanging out with friends is not significant. The same happens for the time spent sporting. Only participation in youth associations is related to positive attitudes such trust and reciprocity. In other words, the attitudinal social capital of the players appears to develop (or at least to be valuable for the creation of trust and reciprocity) only in some specific social contexts. This could happen also because several youth organizations aim at developing and inducing reciprocity and trust through strong

17 Bouckaert and Dhaene (2004) offer experimental evidence which supports this interpretation.

18 They explicitly show that participation to youth organizations develops young people's positive attitudes. 
socialization, while this might not be the main goal of a group of friends, although trust and reciprocity could be assumed among friends. A possible explanation is that friends are a free choice; mates in an association are not completely; hence dealing with them may require some more effort in terms of positive attitudes than dealing with friends. Although this paper does not provide evidence for this interpretation, it is possible that trust and reciprocity are premises for friendship, while socialization within a youth organization fosters trust and reciprocity, and, at the end, what psychologists call "positive development". A secondary though relevant finding is the absence of a significant gender effect in the considered experiment ${ }^{19}$ : in both cases (players A and B) no gender effect is detected.

\section{Appendix: Experimental Form}

Part A

\section{Student A:}

You divide 1,400 NOK between yourself and a Student B. Write down the sum (between 0 and 1,400 NOK) that you want to pass to Student B:

\section{NOK}

Part B

Student B:

You receive three times the amount Student A gave you. Thus, you receive NOK

You divide this amount between yourself and Student A. Write down the sum you pass back to Student A:

\section{NOK}

19 On the debate about the gender effect in a trust game see Croson and Buchan (1999). 


\section{References}

Berg, J. E., J. Dickhaut and K. McCabe (1995), “Trust, Reciprocity and Social History", Games and Economic Behavior, 10, pp. 122-142.

Bouckaert, J., and G. Dhaene (2004), "Inter-Ethnic Trust and Reciprocity: Results of an Experiment with Small Businessmen", European Journal of Political Economy, 20, pp. 869-886.

Brehm, J., and W. Rahn (1997), "Individual-level Evidence for the Causes and Consequences of Social Capital”, American Journal of Political Science, 41, pp. 999-1023.

Caldwin, L. L., and C. K. Baldwin (2003), "The Role of Leisure Time and Recreation Activities in Positive Youth Development", in: Community Youth Development. Programs, Policies and Practices, F. A. Villaruel, D. F. Perkins, L. M. Borden and J. G. Keith, eds, London: SAGE Publication.

Camerer, C. (2003), Behavioral Game Theory. Experiments in Strategic Interaction, Princeton: Princeton University Press.

Claibourn, M. P., and P. S. Martin (2000), "Trusting and Joining? An Empirical Test of the Reciprocal Nature of Social Capital”, Political Behaviour, 22, pp. 267-291.

Croson, R., and N. Buchan (1999), "Gender and Culture: International Experimental Evidence from Trust Games", The American Economic Review, 89, pp.386-391.

Durlauf, S. N., and M. Fafchamps (2004), "Social Capital", in Handbook of Economic Growth, P. Aghion and S. Durlauf, eds, pp. 1639-1699; Amsterdam: Elsevier.

Easterly, W. (2001), The Elusive Quest for Growth: Economists' Adventures and Misadventures in the Tropics, Cambridge: MIT Press.

Eckel C., and P. J. Grossman (2000), "Volunteers and Pseudo-Volunteers: The Effect of Recruitment Method in Dictator Experiments", Experimental Economics, 3, pp. 107-120.

Fehr, E., and K. M. Schmidt (1999), "A Theory of Fairness, Competition and Cooperation”, Quarterly Journal of Economics, 108, pp.437-460.

Furano, K., P. A. Roaf, M. B. Styles and A. Y. Branch (1993), Big Brothers/Big Sisters: a Study of Program Practices, Philadelphia: Public/Private Ventures.

Hansen, D. M., R. W. Larson and J. B. Dworkin (2003), "What Adolescents Learn in Organized Youth Activities: a Survey of Self-Reported Developmental Experiences", Journal of Research on Adolescence, 13, pp. 25-55. 
Harris-White, B. (2003), "India's Pluralism and Its Implications for the Economy", in India Working: Essays on Society and Economy, Cambridge: Cambridge University Press.

Harter, S. (1990), "Self and Identity Development", in: At the Threshold: the Developing Adolescent, S.S. Feldman and G.R. Elliot, eds., Cambridge, MA: Harvard University Press.

Hurtes, K. P., L. R. Allen, B. W. Stevens and C. Lee (2000), "Benefit-Based Programming: Making an Impact on Youth", Journal of Park and Recreation Administration, 18, pp. 34-49.

Jennings, M. K., and L. Stoker (2004), "Social Trust and Civic Engagement across Time and Generations”, Acta Politica, 39, pp.342-379.

Jarret, R. L., P. J. Sullivan and N. D. Watkins (2005), "Developing Social Capital Through Participation in Organized Youth Programs: Qualitative Insights from Three Programs", Journal of Community Psychology, 33, pp. 41-55.

Karlan, D. (2005), "Using Experimental Economics to Measure Social Capital and Predict Financial Decisions", The American Economic Review, 95, pp. 1688-1699.

Kleiber, D. A., and C. E. Kirshnit (1991), "Sport Involvement and Identity Formation", in: Mini-body Maturity: Psychological Approaches to Sport, Exercise and Fitness, L. Diamante, ed., New York: Hemisphere.

Kleiber, D. A. (1999), Leisure Experience and Human Development: A Dialectical Interpretation, New York: Basic Books.

Krawczyk, M. (2011), "What Brings Your Subjects to the Lab? A Field Experiment", Experimental Economics, in press.

Larson, R. W. (1994), "Youth Organizations, Hobbies and Sports as Developmental Contexts", in: Adolescence in Context, R. K. Silbereisen, E. Todt and G. Rudinger, eds, New York: Springer-Verlag.

Larson, R. W. (2000), "Towards a Psychology of Positive Youth Development", American Psychologist, 55, pp. 170-183.

McCabe, K. A., M. L. Rigdon and V. L. Smith (2003), "Positive Reciprocity and Intentions in Trust Games", Journal of Economic Behavior \& Organization, 52 pp. 267-275.

Meier, S., and B. S. Frey (2004), “Do Business Students Make Good Citizens?”, International Journal of the Economics of Business, 11, pp. 141-163.

Migheli, M. (forthcoming), "Assessing Trust through Social Capital? A Possible Experimental Answer", The American Journal of Economics and Sociology.

Putnam, R. (1993), Making Democracy Work. Civic Traditions in Modern Italy, Princeton: Princeton University Press. 
Rich, G. J. (2003), "The Positive Psychology of Youth and Adolescence”, Journal of Youth and Adolescence, 32 pp. 1-3.

Rotemberg, J. (2004), Minimally Acceptable Altruism and the Ultimatum Game, Harvard University, mimeo.

Shah, D. (1998), "Civic Engagement, Interpersonal Trust, and Television Use: an Individual-level Assessment of Social Capital", Political Psychology, 19, pp. 469-496.

Stanley, T. D., and U. Tran (1998), "Economics Students Need not Be Greedy: Fairness and the Ultimatum Game", Journal of Socio-Economics, 27, pp. 657-664.

Stolle, D., and M. Hooghe (2004), "The Roots of Social Capital: Attitudinal and Network Mechanisms in the Relation between Youth and Adult Indicators of Social Capital", Acta Politica, 39, pp. 422-441.

Tierney, J. P., J. B. Grossman and N. L. Resch (1995), "Leisure and Identity Formation in Male and Female Adolescents: a Preliminary Examination", Journal of Leisure Research, 27, pp. 245-263.

Uslaner, E. M. (2002), The Moral Foundations of Trust. New York, Cambridge University Press.

Weissberg, R. P., and M. U. O'Brien (2004), "What Works in School-Based Social and Emotional Learning Programs for Positive Youth Development", The Annals of the American Academy of Political and Social Sciences, 591, pp. 86-97.

Yunus, M. (2003), The Banker to the Poor. Jackson TN: Perseus Publishing.

\section{SUMMARY}

This paper analyzes the contribution of youth's different time allocations to positive behaviors in exchanges. Psychologists highlight that time spent within voluntary organizations fosters positive development. The paper aims at deepening the knowledge of the psychological bases of the observed outcomes of a basic trust game. Undergraduate students played a basic trust game; after this, information about the use of their spare time was collected. Higher passed amounts positively correlate with time spent in youth organizations. The main novelties of the paper are: the way social capital is measured and the strong link with the psychological literature. 